\title{
Lipoteichoic Acid from Staphylococcus aureus Enhances Allergen-Specific IL-5 Production in Patients with Atopic Dermatitis
}

Katsuhiko Matsui ${ }^{*}$, Soichi Tofukuji and Reiko Ikeda

Department of Microbial Science and Host Defense, Meiji Pharmaceutical University, Tokyo, Japan

*Corresponding author: Katsuhiko Matsui, Department of Microbial Science and Host Defense, Meiji Pharmaceutical University, 2-522-1 Noshio, Kiyose, Tokyo 204-8588, Japan, Fax: (+81)-42-495-8677; Tel: (+81)-42-495-8677; E-mail: kmatsui@my-pharm.ac.jp

Received date: May 19, 2017; Accepted date: May 26, 2017; Published date: June 04, 2017

Copyright: () 2017 Matsui K, et al. This is an open-access article distributed under the terms of the Creative Commons Attribution License, which permits unrestricted use, distribution, and reproduction in any medium, provided the original author and source are credited.

\begin{abstract}
The present study investigated the effects of lipoteichoic acid (LTA) derived from Staphylococcus aureus on production of the allergen-specific T helper type 2 (Th2) cytokine, interleukin (IL)-5, in human peripheral blood mononuclear cells (PBMCs) from patients with atopic dermatitis (AD). LTA dose-dependently enhanced the production of allergen-induced IL-5 in PBMCs from patients with AD, but not in those from healthy individuals. Also, when PBMCs from healthy individuals were cultured in a suboptimal concentration of anti-CD3 monoclonal antibody, which alone did not induce IL-5 production, the presence of LTA in the cultures dose-dependently augmented IL-5 production. These results suggest that Th2 cells of $A D$ patients have already been primed by sensitization with various allergens and respond readily to LTA in the presence of an allergen, thus explaining the role of $S$. aureus colonization in $A D$ patients.
\end{abstract}

Keywords: Atopic dermatitis; Staphylococcus aureus, Lipoteichoic acid; Interleukin-5

\section{Atopic Dermatitis and Staphylococcal Lipoteichoic Acid}

Atopic dermatitis $(\mathrm{AD})$ is a chronic inflammatory skin disease with immunopathologic features that vary depending on the duration of the lesions. Patients with AD have been shown to have increased serum levels of IgE, enhanced synthesis of the typical T helper type 2 (Th2) cytokines interleukin (IL)-4 and IL-5 in skin lesions, as well as persistent skin colonization with Staphylococcus aureus [1]. Peripheral blood mononuclear cells (PBMCs) from patients with AD have also been found to produce a significant level of IL-5 in response to stimulation with an allergen, compared with those from healthy individuals [2]. As IL-5 is known to induce the development of eosinophils [1], it may have an important role in the induction of eosinophilic inflammation, and therefore control of IL-5 production from Th2 cells may have potential for management of allergic diseases that are characterized by eosinophilic inflammation. $S$. aureus can be isolated from over $95 \%$ of skin lesions of AD patients, while only $10 \%$ of healthy individuals show skin colonization by this organism [3]. Our previous study suggested that lipoteichoic acid (LTA), a cell wall component of $S$. aureus, might amplify skin inflammation in AD [4]. Furthermore, Travers et al. have demonstrated the presence of high levels of staphylococcal LTA in AD lesions [5]. However, the relationship between LTA and IL-5 production in patients with AD has not been fully elucidated. In the present study, therefore, to assess the role of $S$. aureus colonization in IL-5 production from Th2 cells, the effect of LTA on allergen-specific IL-5 production was investigated using PBMCs from AD patients and healthy individuals.

Lymphocytes were isolated as PBMCs from heparinized venous blood from 10 adult patients with $\mathrm{AD}$ and 10 age-matched healthy controls. All of the patients had been clinically diagnosed by dermatologists as having $\mathrm{AD}$ lesions and had shown positive responses in the skin prick test using house dust mite body extract from Dermatophagoides farinae. None of the subjects had received any systemic or strong topical steroid treatment. The study protocol was approved by the ethics committee of Meiji Pharmaceutical University, and written informed consent for blood sampling was obtained from both the patients and the controls. Cell suspensions containing $2 \times$ $10^{6} / \mathrm{mL}$ viable PBMCs in RPMI-1640 with L-glutamine (SigmaAldrich, St. Louis, MO, USA) containing 10\% donor-derived serum, 25 $\mathrm{mM}$ HEPES buffer (Sigma-Aldrich), $100 \mathrm{U} / \mathrm{mL}$ penicillin and 100 $\mu \mathrm{g} / \mathrm{mL}$ streptomycin (Gibco RBL, Grand Island, NY, USA) were dispensed into each well of 96 -well plates. $D$. farinae-derived mite antigen (MA) was prepared as described previously [4], and used as an allergen at a final concentration of $10 \mathrm{ng} / \mathrm{mL}$. Highly purified LTA derived from $S$. aureus was obtained from InvivoGen (Toulouse, France) and used as a stimulant at a final concentration of 0.01-1 $\mu \mathrm{g} / \mathrm{mL}$. The T-lymphocyte mitogenic monoclonal antibody used in this study was mouse anti-human CD3 monoclonal antibody (clone SK7, IgG1 subclass; BD Biosciences, San Jose, CA, USA) and used at a final concentration of $0.5 \mathrm{ng} / \mathrm{mL}$. Cultures were incubated at $37^{\circ} \mathrm{C}$ in a humidified atmosphere of $5 \% \mathrm{CO}_{2}$ in air. In order to determine the amounts of IL-5 produced, PBMCs were cultured and stimulated as described above. The culture supernatants were collected after incubation for $48 \mathrm{~h}$, and the IL- 5 concentrations were measured using ELISA kits for quantification of human IL-5 (R \& D Systems, Minneapolis, MN, USA). The data were expressed as means \pm SE and differences between them were analyzed using Turkey's multiple comparison test. Differences at $\mathrm{P}<0.05$ were considered to be statistically significant.

To examine the influence of LTA on MA-induced IL-5 production in patients with $\mathrm{AD}$, PBMCs $\left(2 \times 10^{6} / \mathrm{mL}\right)$ from $\mathrm{AD}$ patients were treated with $10 \mathrm{ng} / \mathrm{mL}$ MA in the presence or absence of $0.01-1 \mu \mathrm{g} / \mathrm{mL}$ LTA. After $48 \mathrm{~h}$ of incubation, concentrations of IL-5 in the culture supernatants were measured by ELISA. Figure 1 shows the effect of LTA on MA-induced IL-5 production from PBMCs. PBMCs from AD patients, but not from healthy individuals, responded to MA and 
secreted IL-5 protein into the culture. Furthermore, this IL-5 production was enhanced dose-dependently by stimulation with LTA. However, PBMCs from healthy individuals showed no enhancement of IL-5 production even in the presence of LTA.

Next, PBMCs from healthy individuals were treated with a suboptimal concentration of anti-CD3 monoclonal antibody, and the influence of LTA on these PBMCs was studied. As shown in Figure 2, PBMCs treated with $0.5 \mathrm{ng} / \mathrm{mL}$ anti-CD3 monoclonal antibody showed no induction of cell proliferation and IL-5 production even in the presence of $10 \mathrm{ng} / \mathrm{mL}$ MA (data not shown), but upon stimulation with LTA they proliferated and secreted IL-5 protein into the culture in a dose-dependent manner, as was the case for PBMCs from $\mathrm{AD}$ patients that had been treated with MA and LTA simultaneously.

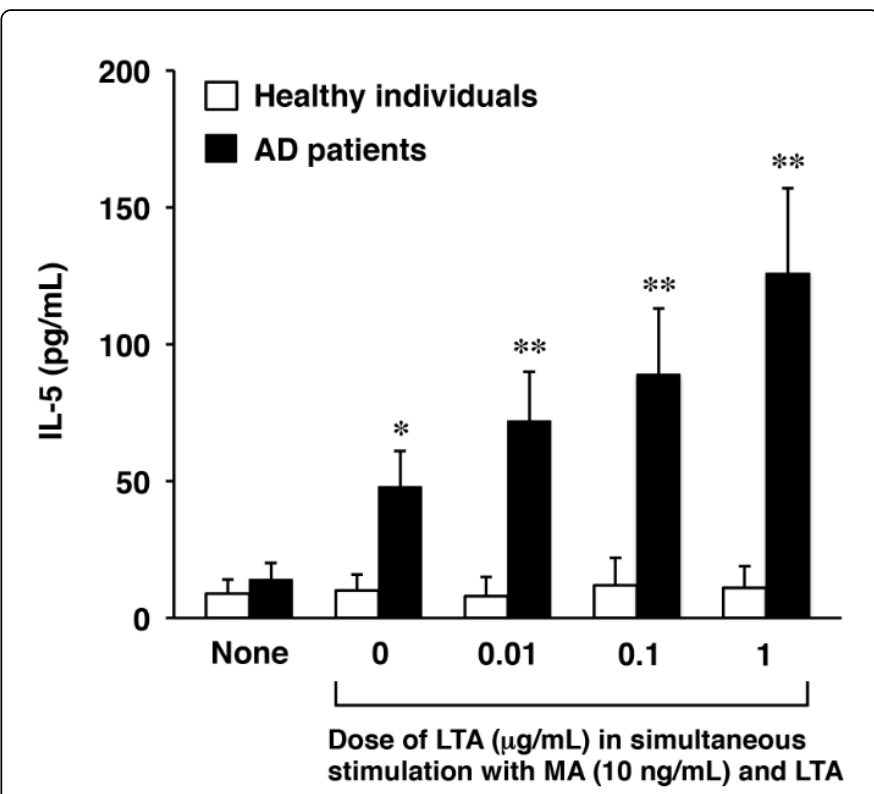

Figure 1: Enhancement of allergen-specific IL-5 production by PBMCs from AD patients in the presence of LTA. PBMCs $(2 \times$ $10^{6} / \mathrm{mL}$ ) from healthy individuals and $\mathrm{AD}$ patients were treated with $10 \mathrm{ng} / \mathrm{mL}$ MA in the presence or absence of $0.01-1 \mu \mathrm{g} / \mathrm{mL}$ LTA for $48 \mathrm{~h}$, and the supernatants were assayed for IL- 5 production using ELISA. The results are expressed as means \pm SE $(n=10)$. ${ }^{*} \mathrm{P}<0.05$ versus non-treatment, ${ }^{* *} \mathrm{P}<0.05$ versus $\mathrm{MA}$ alone $(0 \mu \mathrm{g} / \mathrm{mL}$ LTA).

Our findings indicated that IL-5 production from MA-stimulated PBMCs was marked in AD patients, but not in healthy individuals, suggesting that Th2 cells in $\mathrm{AD}$ patients respond readily to antigens. Considering that $\mathrm{AD}$ patients already sensitized with $\mathrm{MA}$ would have retained MA-specific Th2 cells in their peripheral blood, PBMCs from $\mathrm{AD}$ patients would naturally produce higher levels of IL-5 in response to MA stimulation, relative to those from healthy individuals. Furthermore, our data showed that LTA significantly enhanced the production of IL-5 from MA-stimulated PBMCs derived from AD patients. On the other hand, although PBMCs from healthy individuals did not respond to LTA, they became responsive to LTA in the presence of anti-CD3 monoclonal antibody.

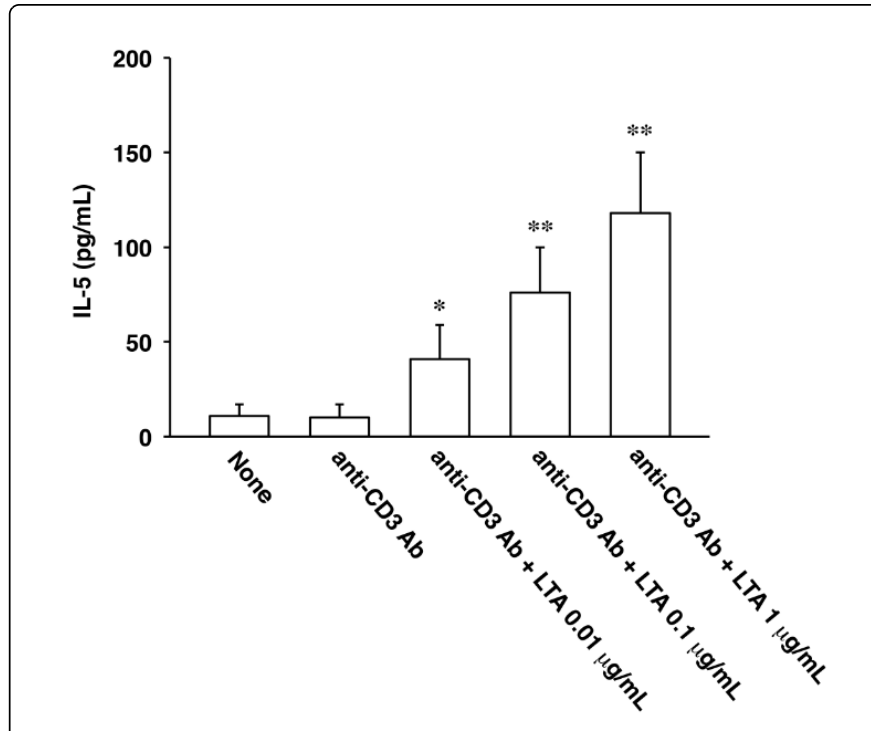

Figure 2: IL-5 production by PBMCs from healthy individuals after simultaneous treatment with anti-CD3 monoclonal antibody and LTA. The PBMCs $\left(2 \times 10^{6} / \mathrm{mL}\right)$ were treated with $0.5 \mathrm{ng} / \mathrm{mL}$ antiCD3 monoclonal antibody in the presence or absence of $0.01-1$ $\mu \mathrm{g} / \mathrm{mL}$ LTA for $48 \mathrm{~h}$, and the supernatants were assayed for IL-5 production using ELISA. The results are expressed as means $\pm \mathrm{SE}$ $(\mathrm{n}=10) .{ }^{*} \mathrm{P}<0.05,{ }^{* *} \mathrm{P}<0.01$ versus non-treatment.

Since the anti-CD3 monoclonal antibody was used at a suboptimal concentration, the antibody alone did not enhance IL-5 production from PBMCs. This indicated that PBMCs from healthy individuals were primed by the suboptimal concentration of anti-CD3 monoclonal antibody, and became ready to respond to LTA. Therefore it is likely that Th2 cells in PBMCs from AD patients may have already been primed by intracellular signaling through the T-cell receptor-CD3 surface complex. Since LTA is known to be a ligand for toll-like receptor (TLR) 2 [5], LTA would probably stimulate the TLR2 of antigen-presenting cells (APCs) among PBMCs. This would enhance the expression of CD80/CD86 on APCs and deliver a second signal to the primed Th2 cells through interaction between CD80/CD86 on APCs and CD28 on Th2 cells, resulting in augmentation of IL-5 production. Therefore, it can be said that LTA works as an adjuvant for allergen-specific IL-5 production in AD patients. On the other hand, it has been reported that innate lymphoid cells (ILCs) are the predominant cellular sources of cytokines, including IL-5 and IL-13, at an early stage after infection [6-8]. Mechanistically, group 2 ILCs (ILC2s) express the transcription factor GATA3 and secrete IL-5 and IL-13 in response to the epithelial cell-derived cytokines IL-25 and IL-33, as well as thymic stromal lymphopoietin (TSLP) [9]. Interestingly, since a recent study has indicated that histone methyltransferase G9a plays an essential role in the regulation of ILC2 development [10], differential secretion of IL-5 upon LTA stimulation of PBMCs derived from $\mathrm{AD}$ patients and healthy individuals might be directly attributable to the differential levels and/or activities of G9a. Furthermore, as G9a maintains histone $\mathrm{H} 3(\mathrm{H} 3 \mathrm{~K} 9 \mathrm{me} 1 / 2)$ as well as DNA methylation epigenetically [11,12], aberrant patterns of these epigenetic markers might also lead to differential secretion of IL-5 in PBMCs. Therefore, investigation of the expression levels and status of G9a and its associated epigenetic markers might shed further light on the mechanisms linked to the present observations. Since the skin of 
Citation: Matsui K, Tofukuji S, Ikeda R (2017) Lipoteichoic Acid from Staphylococcus aureus Enhances Allergen-Specific IL-5 Production in Patients with Atopic Dermatitis. J Allergy Ther 8: 258. doi:10.4172/2155-6121.1000258

Page 3 of 3

most AD patients shows superficial $S$. aureus colonization and barrier disruption due to reduced levels of filaggrin [13], a cell wall component such as LTA would be expected to penetrate the skin easily. Because the density of $S$. aureus in skin lesions of AD patients exceeds $1 \times 10^{5}$ $1 \times 10^{7}$ organisms $/ \mathrm{cm}^{2}$, the LTA concentration of $0.01-1 \mu \mathrm{g} / \mathrm{mL}$ we used for in vitro stimulation would realistically approximate the concentration in vivo $[14,15]$. Thus, irrespective of whether $\mathrm{AD}$ patients show clinical signs of superinfection, anti-microbial therapy might be a promising new strategy for $\mathrm{AD}$ lesions with $S$. aureus infection.

\section{References}

1. Leung DY, Boguniewicz M, Howell MD, Nomura I, Hamid QA (2004) New insights into atopic dermatitis. J Clin Invest 113: 651-657.

2. Okada M, Terui T, Honda M, Tanaka M, Chikama R, et al. (2002) Cutaneous late phase reaction in adult atopic dermatitis patients with high serum IgE antibody to Dermatophagoides farinae: correlation with IL-5 production by allergen-stimulated peripheral blood mononuclear cells. J Dermatol Sci 29: 73-84.

3. Matsui K, Nishikawa A, Suto H, Tsuboi R, Ogawa H (2000) Comparative study of Staphylococcus aureus isolated from lesional and non-lesional skin of atopic dermatitis. Microbiol Immunol 44: 945-947.

4. Matsui K, Nishikawa A (2002) Lipoteichoic acid from Staphylococcus aureus induces Th2-prone dermatitis in mice sensitized percutaneously with an allergen. Clin Exp Allergy 32: 783-788.

5. Travers JB, Kozman A, Mousdicas N, Saha C, Landis M, et al. (2010) Infected atopic dermatitis lesions contain pharmacologic amounts of lipoteichoic acid. J Allergy Clin Immunol 125: 146-152.

6. Moro K, Yamada T, Tanabe M, Takeuchi T, Ikawa T, et al. (2010) Innate production of $\mathrm{TH} 2$ cytokines by adipose tissue-associated c-Kit ${ }^{+} \mathrm{Sca}-1^{+}$ lymphoid cells. Nature 463: 540-544.
7. Price AE, Liang HE, Sullivan BM, Reinhardt RL, Eisley CJ, et al. (2010) Systemically dispersed innate IL-13-expressing cells in type 2 immunity. Proc Natl Acad Sci USA 107: 11489-11494.

8. Monticelli LA, Sonnenberg GF, Abt MC, Alenghat T, Ziegler CG, et al. (2011) Innate lymphoid cells promote lung-tissue homeostasis after infection with influenza virus. Nat Immunol 12: 1045-1054.

9. Artis D, Spits H (2015) The biology of innate lymphoid cells. Nature 517: 293-301.

10. Antignano F, Braam M, Hughes MR, Chenery AL, Burrows $\mathrm{K}$, et al. (2016) G9a regulates group 2 innate lymphoid cell development by repressing the group 3 innate lymphoid cell program. J Exp Med 213: 1153-1162.

11. Shinkai Y, Tachibana M (2011) H3K9 methyltransferase G9a and the related molecule GLP. Genes Dev 25: 781-788.

12. Zhang T, Termanis A, Özkan B, Bao XX, Culley J, et al. (2016) G9a/GLP complex maintains imprinted DNA methylation in embryonic stem cells. Cell Rep 15: 77-85.

13. Kezic S, Jakasa I (2016) Filaggrin and skin barrier function. Curr Probl Dermatol 49: 1-7.

14. Guzik TJ, Bzowska M, Kasprowicz A, Czerniawska-Mysik G, Wójcik K, et al. (2005) Persistent skin colonization with Staphylococcus aureus in atopic dermatitis: relationship to clinical and immunological parameters. Clin Exp Allergy 35: 448-455.

15. Zhang Q, Mousdicas N, Yi Q, Al-Hassani M, Billings SD, et al. (2005) Staphylococcal lipoteichoic acid inhibits delayed-type hypersensitivity reactions via the platelet-activating factor receptor. J Clin Invest 115: 2855-2861. 